\title{
Application of Cultural Symbols of Water Transport of Huaian in the Design of Tourist Souvenir
}

\author{
Yuzhou Wu \\ Huaiyin Institute of Technology \\ Huaian, China 223001
}

\author{
Ping Liu \\ Huaiyin Institute of Technology \\ Huaian, China 223001
}

\begin{abstract}
Application of implement culture in water transport of Huaian to design of tourist souvenir is discussed according to cultural transmission. First, the idea of designing cultural derivatives from material, behavior and reflection is proposed; second, the inheritance and reappearance of water transport culture of Huaian in tourist souvenir design is demonstrated through completing design flow and implementing actual design case; finally, the application of water transport culture to design of tourist souvenir at present is concluded and suggestions are proposed through reflecting on the design scheme.
\end{abstract}

Keywords-Huaian; water transport culture; symbol; tourist souvenir; design

\section{INTRODUCTION}

Located in the intersection of ancient Huaihe River and Beijing-Hangzhou Grand Canal, Huaian is one of the birthplaces of ancient culture in Yangtze-Huaihe river basin. It has beautiful natural environment and plentiful cultural resources: canal culture (water transport culture, water conservancy culture, urban business culture, Quguan culture, religious culture along the canal, water transport of salt in Huaian), wetland culture, Quyi culture, cooking culture of Huaiyang cuisine, history and humanity as well as scenic spots and historic sites. In the new era with the rise of China and culture, we can inherit cultural heritage, redevelop and redesign tradition and promote deep integration of cultural resources with other industries, in order to realize regional economic, cultural and ecological sustainable development. Under this economic and cultural background, analyze water transport culture in Huaian and carry out design innovation through symbolic transmission to make the tourism products in this area unique. Meanwhile, it improves the level of tourism products and meets increasingly high mental demands of tourists for products.

\section{COMMON DESIGN THOUGHTS FOR DERIVATIVES OF IMPLEMENT CULTURE OF WATER TRANSPORT}

Culture represents life style of people. People rapidly feel the image and meaning of implements through cultural implements. Therefore, cultural derivatives are regarded as

The project supported by philosophy and social science fund for universities in Jiangsu "Research on Adaptability of Water Transport Implement Culture in Contemporary Era in the Perspective of Ecological Culture" (2016SJB760087). carrier and symbol of culture. Specifically, according to semiotics, design semantics and theories of experience design, the design of cultural derivatives is considered from three aspects: first is physical form. Analyze forms, materials, color and decoration of traditional implements, extract modeling symbols and redesign to acquire sense of symbol. The superficial symbolic decoration makes people rapidly associate cultural significance. It is suitable for tourist souvenir. Second is behavior. It is the redesign of people's social behavior structure. Different people have different behavioral habits, and the same behavior has different meanings for different people. We can analyze and excavate meaningful behaviors in the culture and transfer it to corresponding products to make it have cultural connotation on spiritual level. It is suitable for design of daily necessities in tourist attractions. Third is the reflection. Make implements represent ideology of culture through designing. It makes consumers profoundly understand the cultural implications. Redesigning water transport implements can base on the three aspects and different objects and objectives.

\section{REDESIGN DERIVATIVES OF WATER TRANSPORT IMPLEMENTS IN HUAIAN}

Formalistic design, behavior design and cultural design must be finally turned into specific symbols. Therefore, the acquisition of cultural symbols with cultural significance is the foundation of all design, in order to carry out further design according to characteristics of implements, cognitive level of users and manufacturing capability of producers.

\section{A. Design Symbols}

Huaiyan has plentiful cultural resources related to water transport implements. They may become creative symbolic resources of redesign. Specifically speaking, it divides into: (1) Resources of geological forms such as Baima Lake, Liyun River, Hongze Lake, embankment of Hongze Lake, distribution diagram of water vein and water transport route. Carry out art processing according to their characteristic forms to turn it into design symbols that represent Huaian culture; (2) Historical material heritage resources, such as Qinghe water gate, Qingjiang $\mathrm{Pu}$ Tower, Zhenhuai Tower, south ship and north horse monument, Qingyan Garden, the District Magistrate Office of Huaian, viceroy yamen of water transport, Hexia Ancient Town, canal reach, ship for water transport, granary and bronze ware, can become derivatives of water 
transport culture in Huaian; (3) Intangible cultural heritage resources such as famous persons and artistic images created by them, traditional ways of food, clothing, housing and transportation, and traditional ideas of creating and using implements brought by water transport (such as eclecticism, craftsmanship and theory that man is an integral part of nature) can be redesigned as derivatives of water transport culture of Huaian.

\section{B. Conception and Creation of Cultural Symbols}

Understand requirements of product positioning through tools of mood board, story board and perceptual map and consumer group, usage situation and product functions and depict concrete forms. In design concept, process cultural resources in physical forms, behavioral patterns and reflection according to different product positioning, extract useful elements and endow it with cultural implications according to characteristics of products and usage situation. In the conception of design originality: first, choose proper cultural symbols. The relevance and matching between design objects and cultural symbols should be clear to make them bring out the best in each other. Second, the transformation of cultural symbols should be proper. The processing of cultural symbols must neither stick to the prototype (may influence usability of goods) nor have nothing to do with the prototype (break away from the original intention of cultural derivatives). Third, the innovation of symbols must be typical. The shaping of cultural symbols cannot go with the tide but highlight characteristics of water transport culture. Third, cultural symbols must be aesthetic. No matter what kind of cultural resources and design thoughts are chosen, the forms of implements must be aesthetic.

\section{Concrete Design Schemes}

Scheme 1: Bronze wares in Huaian Museum are taken as the source of originality of cultural symbol. Abstract the original cultural symbols according to the way of drinking tea in middle class and produce derivatives of water transport culture in Huaian based on forms of implements. Application of the implement makes people feel the long history of water transport culture in Huaian and extends the cultural inheritance of water transport in Huaian. "Fig. 1"

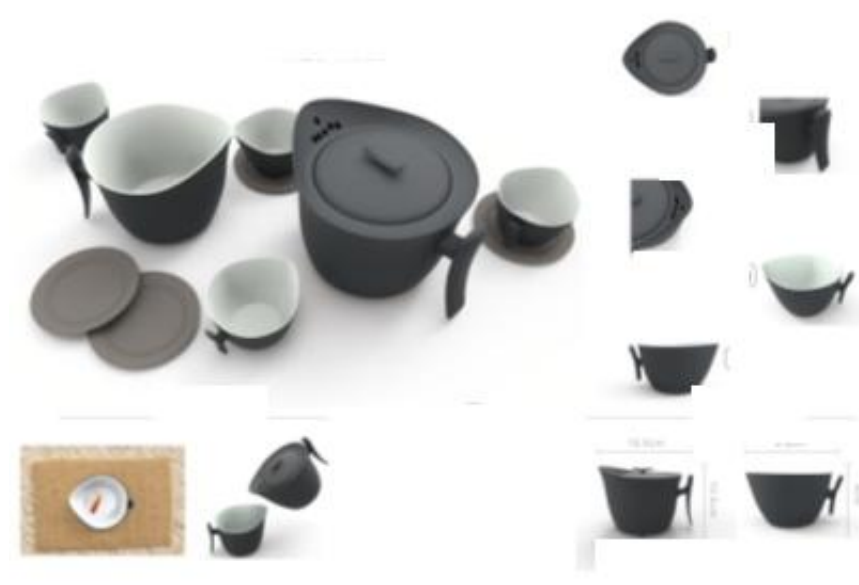

Fig. 1. Black-pottery tea set.

Scheme 2: The image of Sun Wukong in the Journey to the West is taken as design element to redesign in-ear monitor. The earphone head is cylinder-shaped and in-ear. Elliptic cylinder answering button, button to switch music and talklisten button make it concise. Red and yellow on golden cudgel are used. The earphone cable is yellow. The earphone head combines red and yellow, with most part covered by red. The color matching is lively and full of local cultural characteristics of Huaian. The clever combination of the head band of Su Wukong with earphone expands regional culture of Huaian. "Fig. 2"
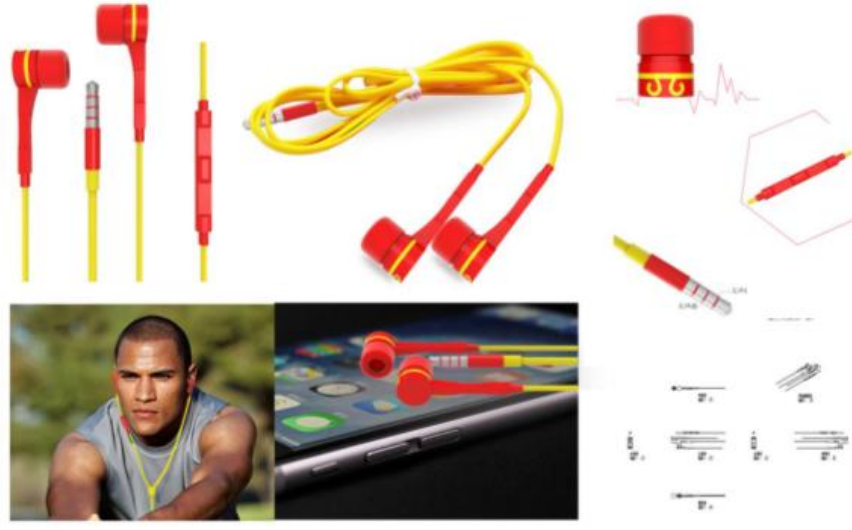

Fig. 2. The Earphone Related To The Monkey King.

Scheme 3: Take the shape of characteristic Baima Lake as cultural symbol and design according to the shape of ship and take sceneries of Baima Lake as surface decoration. The design thought seizes typical elements in the development of water transport culture in Huaian, but it mixes multiple images, which fail to highlight characteristics of "White Horse" and manifest cultural implications and characteristics of water transport in Huaian. However, it shows the characteristics of water culture in Huaian to some extent. "Fig. 3" 

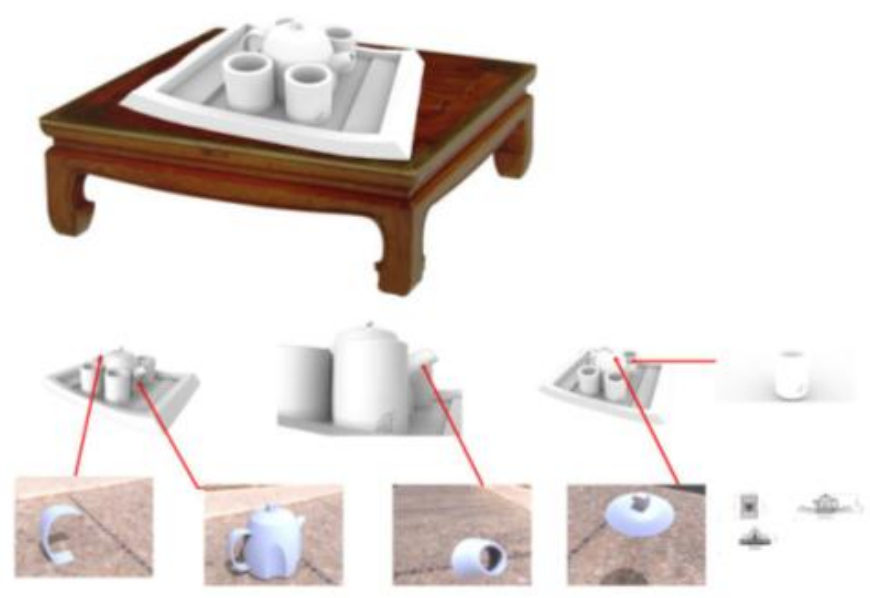

Fig. 3. The tea set in the shape of "White horse Lake".

\section{CONCLUSION}

Redesigning derivatives of implement culture of water transport is to carry out sustainable development of water transport culture in Huaian and improve cultural experience of consumers and users. The diversified culture and cultural consumption require complicated design. At the beginning, designers need to understand connotation and extension of water transport to rapidly and effectively choose cultural resources and elements and explain cultural implications. The integration of cultural symbols in product design can base on tangible and intangible forms to materialize cultural behaviors and thoughts and continue water transport culture. The redesign follows the process of (1) Understand water transport culture in Huaian; (2) make design objects and positioning explicit; (3) choose cultural resources; (4) abstract cultural symbols; (5) create cultural products and explain cultural significance. Key points at each stage are different according to different cultural cognition and characteristics of products. In the design practice of derivatives of implement culture of water transport, the selection and abstract of cultural symbols and its combination with products are priority among priorities. The application of behavior and thoughts related to implement culture of water transport is the difficult point that needs further exploration.

According to the above theoretical thinking and reflection on design practice, in order to redesign derivatives of implement culture of water transport in Huaian, the following suggestions are proposed: (1) Designers need to profoundly understand cultural connotation and the relationship between natural environment, social environment, humanistic environment and culture in cultural formation and development, and then think what kind of forms can make the implement culture better continue in the new environment; (2) In originality design, designers pay attention to regional characteristics of cultural symbols and make cultural symbols more typical and transmissible. The symbols designed should be able to let consumers and users rapidly understand characteristics of water transport culture; (3) The redesign of derivatives pays attention to situation and environment in which consumers and users use, in order to better meet their physiological and psychological needs and receive recognition of them.

\section{REFERENCES}

[1] Donald Arthur Norman, Fu Qiufang. Emotionalized Design [M] Electronic Industry Press, 2005

[2] College of Industrial Design Engineering, Delft University of Technology, Design Methods and Strategies [M], Huazhong University of Science and Technology Press, 2014. 